\title{
Clinical Complications of Type-2 Diabetes Mellitus in South Asian and Chinese Populations: An Overview
}

\author{
Gundu H R Rao ${ }^{1 *}$, Pratiksha G Gandhi ${ }^{2}$ and Vineeta Sharma ${ }^{3}$ \\ ${ }^{1}$ Emeritus Professor, Laboratory Medicine and Pathology, University of Minnesota, USA \\ ${ }^{2}$ Chairperson, IPC Heart Care, Mumbai, India
}

${ }^{3}$ Molecular and Cell Biologist, San Francisco, California, USA

\begin{abstract}
According to recent projections of World Health Organization (WHO), India already leads the world, with the largest number of diabetic subjects. China is fast approaching to claim the number one spot. World Diabetes Federation estimates, that India has over 65 million diabetics and an equal number of pre-diabetics. Major contributors for the development of this chronic disorder are hyperglycemia, insulin resistance, dyslipidemia, hypertension, endothelial dysfunction, obesity, oxidative stress, and metabolic syndrome. Some of the early symptoms related to this altered glycemia include polydipsia, polyphagia, polyuria and changes in the vision. Later clinical complications include vasculopathy, peripheral neuropathy, nephropathy and pre-disposition to infections. Clinical trials have demonstrated the benefits of tight control of hyperglycemia as well as of multiple risk factors. Early detection of hyperglycemia, insulin resistance, altered lipid metabolism and better management of these observed risks, is the best choice we have, to reduce the Global Health Care burden. Excess glucose in the circulating blood seems to impair the endothelial dependent vasodilatation in both the microcirculation as well as macro-circulation. Prolonged exposure to hyperglycemic environment and altered endothelial function seems to accelerate the pathogenesis of atherosclerosis and type-2 diabetes and its clinical complications.
\end{abstract}

Keywords: Hyperglycemia; Hypertension; Obesity; Endothelial Dysfunction; Metabolic Syndrome; Insulin resistance; Type-2 diabetes; Platelet hyper function; Gene therapy

\section{Introduction}

South Asians (Indians, Pakistanis, Bangladeshis and Sri Lankans) have very high incidence of Cardio Metabolic Disorders (CMDs), such as hypertension, atherosclerosis, central abdominal obesity, metabolic syndrome, Type-2 Diabetes (T2D), coronary artery disease, and stroke [1-3]. According to World Diabetes Federation currently we have over 65 million diabetics and an equal number of pre-diabetics. India and China are in race for the first place in number of diabetics. In spite of the fact that large numbers of individuals are at risk, according to reliable sources, $50-70 \%$ of the subjects in China and $30-80 \%$ of the individuals in India are not diagnosed and are therefore left untreated. This is to a large extent due to lack of public awareness and limited opportunities for diagnosis. World Health Organization prediction of losses in national income for China exceeds USD378 billion and for India, USD237 billion (www.cadiresearch.org). To a great extent the increase in the incidence of type- 2 diabetes, is attributed to the changes in the life-style, diet, lack of physical activity that promotes obesity. Although type-2 diabetes has increased significantly over the years in China and India, it continues to increase at a fast rate in the USA, as well as other countries across the world. In other words, the world epidemic of type2 diabetes is affecting both the developed and developing countries. Vascular complications related to diabetes accounts for the majority of economic burden worldwide. About one half of the diabetics die prematurely due to cardiovascular complications and a tenth due to renal failure. In spite of the fact that there is an increase in the incidence of this disease worldwide, the major share of the morbidity and mortality is predicted to occur in the resource poor countries. Various risk factors that promote diabetes and vascular disease are known. Although these risks are modifiable or preventable, there are very little efforts in progress in majority of the developing world, to monitor or control them. Known risks include, impaired insulin secretion, insulin resistance resulting in hyperglycemia. Some of the early symptoms related to this altered glycemia include polydipsia, polyphagia, polyuria and changes in the vision. Later clinical complications include vasculopathy, peripheral neuropathy, nephropathy and pre-disposition to infections. Other than the earlier symptoms, the only diagnosis used by and large, is measuring plasma glucose or glycosylated hemoglobin. Management is through lifestyle changes, diet modifications, exercise, drugs that modulate the blood glucose levels. Clinical studies have demonstrated that adequate glycemic control reduces the clinical complications associated with this disease. We strongly believe, that the early detection and better management of the observed risks, is a better choice to reduce the economic burden of this disease worldwide. In this overview, we will discuss the clinical complications associated with these chronic metabolic diseases and suggest some ways, to better manage the observed risks.

\section{Fetal Origin of CMDs}

Since we firmly believe, that the early detection of the risks for CMDs and effective management of the risks is the best choice we have for reducing the Global burden of these metabolic diseases, we will have to start our prevention strategies at the earliest. What is the earliest stage that we can start prevention strategies? According to the seminal epidemiological work at the Mission Hospital, Mysore, India, thirty

*Corresponding author: Gundu H R Rao, Emeritus Professor, Laboratory Medicine and Pathology, University of Minnesota, 420 Delaware St SE, Minneapolis, Minnesota 55455, USA, Tel: 952594 5248; E-mail: gundurao9@gmail.com

Received May 07, 2014; Accepted August 27, 2014; Published September 05 2014

Citation: Rao GHR, Gandhi PG, Sharma V (2014) Clinical Complications of Type2 Diabetes Mellitus in South Asian and Chinese Populations: An Overview. Diabetes Metab 5: 420 doi:10.4172/2155-6156.1000420

Copyright: ( 2014 Rao GHR, et al. This is an open-access article distributed unde the terms of the Creative Commons Attribution License, which permits unrestricted use, distribution, and reproduction in any medium, provided the original author and source are credited. 
percent of the children born in India, are of low birth weight. The birth record of all the children born in this hospital is maintained from 1936. In view of this meticulous record keeping, Medical Research Council (MRC) of UK has set up an epidemiology wing at this hospital. Studies from this group on "Mysore Cohort" for decades, have established that these children as they grow up have a higher risk of developing metabolic diseases, such as hypertension, obesity, metabolic syndrome, heart disease and stroke [4-12]. These findings are not unique to South Indian children. Studies on the effect of low birth weight on the development of metabolic syndrome, has been investigated in the Fetal Origin of Adult Disease (FOAD) "cohort" of Beijing, China [13-15]. Several studies have demonstrated fetal origin of metabolic diseases and supported the thrifty phenotype hypothesis of Barker, which proposes that survival physiology and metabolism are altered under condition of poor fetal nutrition, as an adaptive response, these alterations affect the long term metabolism of these cohorts.

\section{Excess Weight and CMDs}

According to National Institutes of Diabetes, Digestive and Kidney Diseases of National Institute of Health, USA, approximately two-thirds of all adults in the USA (167 million), are overweight and a third are obese. The WHO estimates that there are 1.3 billion overweight adults globally. Of these 300 million are clinically obese. According to National Health and Nutritional Examination Surveys (NHANES 1, 11,111) the crude prevalence of excess weight and obesity (BMI>25.0) for those aged $>20$ years was $59.4 \%$ for men and $54-9 \%$ for women. Obesity is an important modulator of various risks associated with vascular diseases, including insulin resistance. The association of excess weight with type-2 diabetes and insulin resistance is well recognized [16]. Insulin resistance is also linked with a variety of associated risks including hypertension, hyper-lipidemia, atherosclerosis, metabolic syndrome, and endothelial dysfunction. However, not every obese individual will have insulin resistance. Furthermore, there are millions of lean subjects who have insulin resistance. The specific mechanism by which enlarged adipose tissue induces systemic insulin resistance is not known.

South Asians have a high incidence of T2D and cardiovascular disease, despite a low prevalence of obesity. Based on a collaborative study done at the Madras Diabetes Research Foundation (MDRF), Chennai, India, and the staff of University of Minnesota, a hypothesis was developed to explain the increased burden of T2D in this population. They hypothesized, that the increased risk might be due to a high propensity towards the abdominal fat or visceral fat accumulation in the South Asian population. To account for the differences in body size and general adiposity between the populations (Caucasians and AfroAmericans and South Asians) they divided the waist circumference by the BMI. The waist/BMI ratio was significantly higher for Indian Men and Women, compared with all US races/sex groups. Results of these studies and that of many others have demonstrated that the South Asian population has excess visceral fat deposits, relative to overall body distribution [17]. If visceral fat is the "bad guy" then the milliondollar question is, does people undergoing liposuction get the benefit of losing this bad fat? If they do get benefit, then how long will it lost? BMI is the most frequently used index of obesity; however, recent studies have shown that the body composition, than the size, may be more relevant risk factor [18]. Studies on Native Americans by Gray et al. have reported that obesity had a modest influence on risk factors for coronary artery disease, and that waist circumference had no special effect over BMI, on risk factors. They concluded, that American Indians might differ in many ways, including lifestyles and body composition; they may also differ widely in obesity and associated risks [19].

\section{Endothelial Function and CMDs}

Pathogenesis of atherosclerosis and associated vasculo-pathies begins in childhood and it is accelerated, with increase in body weight. Endothelium the largest organ system of the body, which lines all the blood vessels, plays a very important role in the vessel wall physiology and function. To a large extent, the vessel wall compliance and the flow of blood are modulated by a fine balanced production of the vasodilators and vasoconstrictors. Altered state of the vascular endothelium known as endothelial dysfunction, is the earliest clinically detectable stage of the cardiovascular disease. Known risk factors such as high cholesterol, high blood pressure, smoking, aging, chronic infection and inflammation can all disrupt normal physiology and function of the endothelium and lead to endothelial dysfunction. Aaron Kelly and associates in St. Paul Heart Clinic, St. Paul, Minnesota, followed a group of overweight children with known endothelial dysfunctions, as they participated in four-times-weekly exercise sessions on a stationary bike. After just eight weeks, the exercise group demonstrated dramatic systemic improvement in vascular health, with endothelial functions returning to normal [20-23]. The study participants did not lose weight nor reduce the body fat. This clearly demonstrates that if kids get to exercise early enough, regardless of being overweight, can have a chance at healthy life. In a separate study, Hambrecht and associates showed that exercise training improves endothelium dependent vasodilatation both in epicardial coronary vessels as well as in resistance vessels, in patients with coronary artery disease [24,25].

\section{Mechanisms Underlying Diabetes-related Clinical Complications}

By and large, the major goals in caring for patients with diabetes are to prevent, or at least slow, the development of clinical complications such as; Micro-vascular (eye and kidney disease), accomplished though control of blood sugar and blood pressure; Macro-vascular (coronary, cerebro-vascular, peripheral vascular), through control of lipids, hypertension and smoking. However, we do not know how the elevated levels of blood glucose, circulating insulin, and altered blood pressure modulate the patho-physiology of the blood vessels and induce severe dysfunction of this system. For instance, obesity has been associated with type- 2 diabetes for several decades. The major basis for this link is the ability of obesity related altered lipid metabolism and its relationship with observed insulin resistance. Insulin resistance is linked with a variety of disorders such as hypertension, hyperlipidemia, atherosclerosis and metabolic syndrome. According to some recent studies, obesity may be a proxy than the cause, for insulin resistance. In the USA alone, there are 30 million individuals, who are obese with no insulin resistance. On the other hand, there are 6 million lean people, who have insulin resistance. Little is known about how the epigenetic factors such as the food that we eat modulates gene expression, in terms of proteomic and metabolomics. These are very important problems. However, future scientific studies could provide answers to such complicated questions.

Therefore, in the absence of such a knowledge base, the current strategies revolve around management of known risks. If we need to manage this chronic disease better, it is essential to understand the genomic, proteomic and metabolomic alterations that predispose the individuals, to develop these cardio-metabolic disorders. It is also important to understand the various gene expressions, mutations and polymorphisms that modulate the clinical complications of this chronic metabolic disease. If we can find gene expressions that modulate the risk associated with various clinical complications and associated earlier 
biomarker expressions that promote this pathological process, then we can customize management strategies. Diabetes is a serious disorder mainly due to its clinical complications. Control of postprandial hyperglycemia by intensive insulin therapy or by some other drug with similar action, is fundamental to prevention of diabetic complications. The NIH sponsored Diabetes Control and Complications Trial (DCCT) which included 1400 randomized subjects, clearly demonstrated beneficial effects of tight control of blood glucose on progression of retinopathy, nephropathy and neuropathy in patients with IDDM [26]. One half of all the diabetics end up with Vascular Diseases of one sort or the other. Ten to Twenty percent of the diabetics develop kidney disease. Diabetes is the most frequent cause of non-traumatic lower limb amputation. Diabetes related complication also includes, retinopathy, which is the term used for all the abnormalities of the small blood vessels of the retina caused by diabetes, such as weakening of blood vessel or leakage from blood vessels. Therefore, it is essential to prevent damage to both macro-and microvasculature in order to prevent these observed clinical complications.

\section{Hyperglycemia and CMDs}

Since everything that we know about diabetes revolves around increased levels of blood glucose, it is important for us to understand, the effect of elevated glucose on vessel wall physiology and function. Hyperglycemia in diabetes causes non-enzymatic glycation of free amino groups of proteins and leads to their structural and functional changes and formation of glycation end products called AGEs [27]. AGEs are directly implicated in the development of chronic complications such as nephropathy, retinopathy, neuropathy and other related diseases such as atherosclerosis, heart disease, stroke and peripheral vascular disease [28]. Researchers in this area have been suspecting that increased modification of proteins by a glucose-derived molecule is a key player in the vascular pathology associated with hypertension, endothelial dysfunction, stroke and obesity. Although most of the glucose in the blood goes directly into the cells for building of energy source (ATP), small portion (5\%) is converted to a molecule O-GlcNAc, which can glycate a variety of proteins and modify their function. This molecule also competes with another mechanism in cells called phosphorylation. In blood vessels, this mechanism modulates the enzyme (nitric oxide synthetase), which produces the vasodilator nitric oxide. Researchers, Rita C Tostes and associates at Medical College of Georgia, are conducting animal studies to test this mechanism, to further explore the mechanism by which the elevated blood sugar alters vessel wall physiology and function (http://phys.org/news161269678. html). Akabri et al. demonstrated the ill effects of blood sugar in human subjects. They showed that, the ingestion of glucose over load impairs the endothelial dependent vasodilatation in both micro- circulation and the macro circulation. Based on the results of their study they speculated, that prolonged hyperglycemia and endothelial dysfunction may lead to the early, accelerated atherosclerosis and diabetes [29].

As we have discussed earlier, clinicians by and large, manage diabetes exclusively based on the levels of fasting glucose and in limited cases, based on HbAlc values. For instance in India, it is common to find people indulging in five meals a day. If we consider that after each meal there is increase blood sugar for at least two hours, then one can see that in these individuals there will be excess blood sugar for more than ten hours. Hyperglycemia both in acute as well as chronic situations has ill effects on vessel wall physiology and function as well as on other functionalities. For instance, it has been reported that the hyperglycemia causes functional decline of neutrophils [30]. Infection thus is a main problem resulting from glucose toxicity. It is also supposed to promote apoptosis of other cells (stem cells). Hyperglycemia induced oxidative stress induces higher levels of superoxide. In animal models this type of stress has been shown to be involved in retinopathy. In view of these observations, there are indications for the use of antioxidants as treatment perspectives [31-35]. According to Rolo and Palmeira four major molecular mechanisms have been implicated in hyperglycemia-induced tissue damage: activation of protein kinase $\mathrm{C}$ isoforms, increased hexosamine pathway, increased Advance Glycation End product (AGE) formation, and increased polyol pathway. Hyperglycemia-induced overproduction of superoxide seems to be the causal link between high glucose and tissue injury [36]. Mutations in mitochondrial DNA (mtDNA) and decreases in the copy number have been linked to the pathogenesis of T2D. Lee and associate have shown an independent association between peripheral blood (leukocytes) mtDNA content and visceral adiposity [37]. They conclude that the mtDNA copy number is a potential predictive marker for metabolic disturbances.

\section{Metabolic Syndrome (Syndrome-X) and Clinical Complications}

Clustering of multiple cardiovascular risk factors is known for several decades. The term "Metabolic Syndrome" is currently used to refer to the clustering of metabolic risk factors, including abdominal obesity, atherogenic dyslipidemia, hypertension, glucose intolerance and a pro-thrombotic inflammatory state [38-44]. Several epidemiological studies have confirmed the occurrence of metabolic syndrome in various ethnic groups such as Caucasians, African Americans, Mexican Americans, Asian Indians, Chinese, Australian Aboriginals, Polynesians and Micronesians [41]. Individuals with this syndrome have two times higher risk for mortality due to Myocardial Infarction (MI) or stroke, and three times likely to develop MI or stroke compared to those who do not have these risks. They seem to have five-fold risk of developing type-2 diabetes. Definition of metabolic syndrome has been introduced by professional societies and world bodies such as World Health Organization (WHO), European Group for the study of Insulin Resistance (EGIR), National Cholesterol Education Programme and Adult Treatment Panel 111 (NCEP-ATP111) and by the International Diabetes Federation (IDF). Therapeutic approach involves intervention at a macro-level and control of multiple risk factors using life style changes, pharmacotherapy for control of obesity and visceral obesity, as well as for other individual risk factors. Major risk factor interventional trial (MRFIT) demonstrated the benefits of multiple risk factor control (www.trialresultscenter.org/study7914-MRFIT.htm). It was a randomized study of over 12,800 subjects grouped according to either special intervention, stepped up care for hypertension or counseling for cigarette smoking.

\section{Platelet Hyper-function and Clinical Complications}

So far we have discussed some of the known risk factors for T2D, such as hyperglycemia, insulin resistance, obesity and metabolic syndrome. When it comes to managing such a complex disease, it is important to consider the not so common risks as well, so that a customized holistic treatment protocol can be developed. There is increasing evidence suggesting that the inflammatory mediators play a pathogenic role in the atherogenesis as well as in acute coronary syndromes [44-46]. Several recent studies suggest, that inflammatory cytokines such as tumor necrosis factor (TNFalpha), Interleukin (IL-1) and various chemokine (IL-8) may activate matrix metalloproteinase and induce degradation of connective tissue and promote apoptosis of cells in the atherosclerotic lesion, thus promoting plaques 
destabilization and rupture. There is considerable evidence to show that platelets contribute significantly, to the pathogenesis of acute coronary syndromes by facilitating thrombus formation. They may also trigger acute coronary events by other mechanisms including stimulation of an inflammatory response within the atherosclerotic plaque. They secrete a wide range of growth factors and inflammatory mediators [47-49]. In addition, they activate other cells such as monocytes and macrophages and promote the expression of tissue necrosis factor and tissue factor. They also modulate the function of leucocytes and promote the expression of chemotactic and adhesive properties of endothelial cells as well as IL-1 production in smooth muscle cells. Increased leucocyteplatelet aggregation has been demonstrated in acute myocardial infarction and cerebral infarction. It has been shown that release of CC-chemokine RANTES by platelets triggers the arrest of monocytes on inflamed atherosclerotic endothelium. Furthermore, in vulnerable plaque significant amounts of tissue factor expression also has been demonstrated. It is clear from the available evidence, that several platelet-derived factors both membrane bound (p-selectin, $\mathrm{p}$-CD40L) as well as soluble (s-selectin, $\mathrm{sCD} 40 \mathrm{~L}$ ) are involved in the inflammatory response mediated by the activation of platelets, leucocytes, monocytes, macrophages and endothelial cells. Some studies have demonstrated the presence of platelet activation markers such as P-selectin and CD40 in patients with MI. There is some evidence to suggest that over expression of CD40L on platelets is correlated with the need for re-angioplasty. Expression of this protein promotes the expression of adhesion molecules, chemokine and inflammatory cytokines and recruitment of leucocytes within the vulnerable plaque. Levels of circulating markers of inflammation, C-Reactive Protein (CRP) has been found to be higher in patients with unstable coronary syndromes $[49,50]$. Furthermore, according to Harvard researchers, persistent elevation of C-reactive protein in patients with unstable angina seems to be a good predictor of future coronary events such as ischemia and MI [51].

\section{Vascular Dysfunction and Clinical Complications}

Functional and structural changes in the arterial wall precede the development of atherosclerosis. Obstructive coronary artery disease may even serve as an early marker for the hypertensive disease [5254]. Function and structural changes of vascular Endothelial Cells (ECs) are modulated by a variety of thrombogenic factors as well as anti-thrombogenic factors $[55,56]$. Some of the vasoactive compounds released by the ECs include vasodilatory compounds such as adenosine, prostacyclin and nitric oxide and vaso-constrictory molecules like, cyclo-oxygeanse derived Endothelium Dependent Constriction Factor (EDCF), hypoxia-induced endothelium dependent constriction factor and endothelin. Lipid peroxides, oxidized lipids and lipoproteins promote the formation of vasoconstrictors by platelets [57]. These lipid mediators inhibit enzymes that promote the formation of vasodilators by the healthy endothelium and lower endogenous production of vasodilators. Alterations in the balance between platelet associated vasoconstrictors and EC-derived vasodilators results in the vascular dysfunction [25-28]. This is probably the earliest stage at which one can detect the manifestation of the arterial dysfunctions, hypertension and atherosclerosis. Indeed, one can classify the risk according to the level of EC dysfunction and additional CAD risk factors present. One can use acetylcholine, L-arginine, and nitric oxide synthetase inhibitor, LNNMA and monitor the flow response in the forearm, to determine the degree of EC dysfunction [58]. Alternatively, one can use CV Profiler (DO-2020, Hypertension Diagnostics, and Eagan, Minnesota) or Periscope (Genesis Medical Systems, Hyderabad) and monitor the pulse waveform of the small arteries [59].

\section{Management of Hyperglycemia, Diabetes and its Clinical Complications}

Diabetes is a major public health problem of global importance. With the increase in age of the global population, incidence of this chronic complex disease is growing in alarming proportions. According to Dr Venkat Narayanan of Center for Disease Control (CDC), Atlanta, Georgia, USA, diabetes is a common, growing, serious, costly and potentially preventable global public health problem [60]. In view of these observations, a multidisciplinary team of health professionals should provide diabetes care with expertise in diabetes management, working in collaboration with the patient and family. However this is not the way it is done in majority of countries. The current treatment strategies revolve around management of known risks. By and large, the major goals in caring for patients with diabetes are to prevent, or at least slow, the development of clinical complications, Diabetes is a serious disorder mainly due to its clinical complications. Control of postprandial hyperglycemia by intensive insulin therapy is fundamental to prevention of diabetes related clinical complications [26]. Having said that, the question is, can we accomplish such a tight control of postprandial glucose (2hPPG), by other treatment modalities? This approach of tight control of $2 \mathrm{hPPG}$ also seems to be useful in including the pre-diabetics into the prevention program. In view of this prevention strategy, it should be of great interest for the developing world, to evaluate and develop alternate therapies using indigenous and traditional medicine. Using Indian or Chinese Traditional Knowledge Systems, it is possible to bridge the current innovation deficit and open entirely new avenues of research and practices to facilitate a better healthcare.

\section{Integrated Approach to the Management of CMDs}

Integrative medicine is an approach to health care, which can be easily incorporated by all medical specialties and professional disciplines including Indian and Chinese Traditional Health Systems and by all other health care systems worldwide [61]. Although traditional therapies are well accepted in India and neighboring countries including China, European Union and USA have not approved these therapies. In recognition of the growing body of evidence in support of Traditional or Alternate Medicine, in February of 2009, Institute of Medicine (IOM) of NIH, USA, organized a summit on Integrative Medicine. The IOM summit summary states, "The disease driven approach to healthcare has resulted in spiraling costs. The first priority for any health care system using and integrative approach is, to ensure that the full spectrum of preventive opportunities-clinical, behavioral, social, spiritual and environmental are included in the care and delivery process". Over 50 US Academic Institutions have Complementary and Alternative Medicine (CAM) programs funded by the National Center for Complimentary and Alternate Medicine (NCCAM). Therapeutic aspects of Traditional Medicine in which herbal products or herbal preparations are used have no place in this system. According to Dr. Josephine Briggs the Director of NCCAM/NIH, the evidence base for these approaches using modern rigorous methods of randomized trials is quite thin. However, according to a recent report in New York Times article dated April 22, 2014, titled, "A top Hospital Opens Up to Chinese Herbs as Medicines', Cleveland Clinic, one of the country's top hospitals, has opened up an "herbal clinic". In addition, Northwestern University and North Shore University Health System affiliated to University of Chicago, both include herbal medicine among other treatment modalities offered.

Professor Bhushan Patwardhan, a well-known scientist of great 
repute, from Pune, India, suggests, that with the help of Indian Traditional Knowledge systems, it is possible to bridge the current innovation deficit and open entirely new avenues of research and practices to facilitate a "rebirth of health care" in countries like India and China, who have ancient arts of traditional healing systems [61]. Till such a novel new approach is developed to bridge the inequities in current healthcare, we will have to consider what other known observation-based or evidence-based remedies are available for better management of diabetes related risk factors. Considering the large number of children born with low birth weight, we need to develop an appropriate nutritional supplement that will provide daily minimum requirement for would be mothers and growing child, to prevent intrauterine complications induced by insufficient nutrition. In the absence of an "all inclusive" healthy diet, it seems that a diet similar to Mediterranean-style diet, including a lower calorie content of refined carbohydrates, high content of fiber, moderate content of fat (preferably unsaturated) and moderate to high content of vegetable proteins are recommended $[62,63]$. Studies also have shown that insulin resistance and endothelial function are improved after folate and Vitamin B12 therapy, in patients with metabolic syndrome [64]. Omega-3 fatty acid supplements have been shown to improve the cardiovascular risk profile of subjects with MS, including markers of inflammation and auto-immunity [65]. Acetyl-L-carnitine has been shown to ameliorate hypertension and insulin resistance in subjects with increased risk for CVD [66].

We at the IPC Heart Care, Mumbai, India (www.ipcheartcenter.com) are evaluating, green tea of mulberry as well as green tea from regular tea leaves as supplements to manage postprandial hyperglycemia. A major green tea polyphenol, epigallocatechin-3-gallate, inhibits obesity, metabolic syndrome and fatty liver in high-fat-fed mice model [67]. In addition to the tea mentioned above, we also are evaluating D-ribose, L-arginine, Curcumin, Carnitine, Resveratrol, Anthocyanin-rich blue-berry extract, citrus-derived flavonoid Narangenin, grape seed extract Procyanidon, green tea extract Tegreen, mulberry leaf extract 1-deoxynojirimcin (DNJ), water soluble extract of cinnamon and coffee (Green Coffee), and hibiscus tea. Based on the results of our studies, we plan to develop a "poly-pill" with indigenous phyto-chemicals for the management of postprandial hyperglycemia. Since we use TMOxi system (LD-Technologies, Miami Florida) to monitor risk profile of patients, we can evaluate various indigenous therapies for their effectiveness or otherwise, in managing the observed risks of MS, T2D and CVDs, using this non-invasive diagnostic platform.

\section{Emerging Technologies: Early Detection and Management of CMDs}

There is a great need for the development of a non-invasive comprehensive diagnostic platform, for early detection of cardiometabolic disorders such as, hypertension, central abdominal obesity, metabolic syndrome, Type-2 diabetes, various vasculopathies, heart disease and stroke. Several studies have demonstrated the usefulness of monitoring health of the blood vessels by using techniques that measure, Intima-Media Thickness (IMT), Pulse Wave Velocity (PWV), Ankle-Brachial Index (ABI), Carotid Duplex Ultrasound (CDU) Index, and Vessel Wall Plaque Volume (3D Carotid Ultrasound). Although many methodologies are available for early detection of altered vascular function, the most widely used method is monitoring aortic Pulse Wave (PWV). With the advance in technologies, now it is possible to use multiple technologies and build a comprehensive risk assessment platform. It is also possible to add capabilities for risk prediction in such a platform. Availability of such a diagnostic platform will facilitate the surveillance of cardio-metabolic disorders at the community level. To accomplish our goals, we need a multi-functional diagnostic platform. Therefore, we have approached Bio Medical Electronics Group of BMS Engineering College, Bangalore, as well as National Design Research Forum (NDRF), Bangalore, India, to help us develop such a medical device development platform. Genesis Medical Systems, Hyderabad, India, is working for several years on the development of non-invasive Point-Of-Care devices for cardiovascular applications. Since they already have several non-invasive devices for monitoring vascular function, they can develop a comprehensive Cardio-Metabolic Risk Profiler (CMRP), to meet our requirements. We are collaborating with them not only in the development of CMRP, but also in the validation studies of their all-in-one device under development, at our clinic in Mumbai (IPC Heart Care Clinic) and in California.

In the meantime, we are looking at the available POC devices worldwide, which can be used for early detection of cardio-metabolic disorders such as hypertension, glucose intolerance, type-2 diabetes and its clinical complications. LD Technologies of Miami, Florida (www.ldteck.com) specializes in the development of non-invasive Point-Of-Care devices. They have put together a platform called "RISC", (for Life Span, India), which uses Autonomic Nervous System (ANS) tests, Heart Rate Variation (HRV) tests, SudoMotor Function tests, and The TM-Oxi system. The diagnostic platform used at the IPC Heart Care (TM-Oxi), Mumbai and the Life Span Kiosks (RISC) in different cities in India, is a combination of many devices and uses photoplethysmography, spectrophotometry, oscillometry and galvanic skin response technologies and displays data rapidly. The scores for various functional tests are color-coded (green orange, yellow and red) and printed out graphically as well as digitally. It generates impressive diagnostic reports with some recommendations. What we need today is a combination of these POC methodologies, for early detection of the altered physiology and function of blood vessels. In addition to these POCs, we should develop the ability to integrate other observed risk factors, to the data collected from such devices, to improve the risk score, so that one could use such comprehensive approach, to the early detection of vascular dysfunction, follow the progression and regression of the vascular disease and manage these diseases effectively.

\section{Gene Therapy: Management of Diabetes Related Clinical Complications}

Gene therapy is a method to replace mutated or diseased gene with a normal gene. Gene therapy based treatment provides long-term and sustained expression of the targeted gene. In gene therapy, gene of interest is packaged inside a carrier molecule. This carrier can be an engineered virus, liposome, arginine-grafted cyctaminebisacrylamidediaminohexane polymer (ABP) or a nano-complex. Non-viral methods can present certain advantages over viral methods, such as large-scale production and almost no host immunogenicity. Numerous non-viral gene delivery methods are under development for Glucagon-Like Peptide (GLP1) gene delivery. Oh et al. [68] reported that a single intravenous injection of Polyethylenimine (PEI)/pGLP1 complex comprising a modified GLP cDNA in Zucker Diabetic Fatty (ZDF) rats resulted in an increase in glucose-induced insulin secretion with a reduction in blood glucose level for 2 weeks. Jean et al. reported a significant increase in the amount of plasma GLP-1 after chitosanGLP-1 nanoparticles injection in ZDF rats [69]. This method improved glucose tolerance and reduced weight gain in the treated rats, but the increase in circulating insulin was transient. Non-viral gene therapy methods are safer; however, this drug delivery approach provides only transient effects $[68,70]$. 
Viral vectors are currently the best choice for gene transfer. There are various virus vectors that are being used for human gene therapy such as retrovirus, lenti virus, adeno virus and Adeno-Associated Virus (AAV). Among the viral vector tested, retroviral vectors have ability to transform their single stranded RNA genome into a double stranded DNA molecule that stably integrates into the target cell genome. Recently, retroviral vector-mediated gene transfer has been reinvigorated with the development of lentiviruses. Lentiviral infection has several advantages including high-efficiency infection of dividing and non-dividing cells; integration property of lentivirus into the host cell genome provides long-term stable expression of a transgene, and low immunogenicity [71]. However, there are many concerns such as, possible generation of replication competent lenti viruses during vector production and insertional mutagenesis leading to cancer [72]. All these safety concerns limit the use of retro and lenti virus in human gene therapy.

Adenoviral vectors are very efficient in transducing a wide range of tissues and offer an ability to infect both dividing and non-dividing cells, to produce high titer yield and accommodate large transgenes [73]. However, adenovirus elicits severe immune response, which limits the longevity of transgene expression [74]. Similar to adenovirus vectors, AAV-based vectors can infect both dividing and non-dividing cells. These vectors elicit only minimal immune response and hence are safer to use in human gene therapy studies. However, there are certain limitations of AAV vectors such as their reduced transduction efficiency and limited transgene capacity $[75,76]$. To increase the transduction efficiency researchers developed double-stranded (ds) AAV vectors by generating mutations at the ITR resulting in the preferential packaging of double-stranded, hairpin-like DNA dimers into AAV capsids [77]. Researchers are continuously modifying traditional AAV based gene therapy approach to make it more feasible for type 2 diabetes treatment.

Riedel et al. used DsAAV8- MIP construct with GLP-1 to assess therapeutic efficacy of GLP-1 via intra-peritoneal injection into diabetic mice. This approach provided protection from hyperglycemia in injected mice [78]. In another study dsAAV vector-mediated delivery of GLP-1 and N and K1 domains of human growth factor (HGF) delayed diabetes onset in $\mathrm{db} / \mathrm{db}$ mice inducing pancreatic islet cell proliferation [79]. Recently, AAV5 mediated Exendin-4 delivery into the salivary glands resulted in sustained Exendin-4 expression at pharmacological levels in blood and salivary glands of diabetic animals [80]. This approach leads to improved glycemic control and insulin sensitivity associated with weight loss $[81,82]$. Although, some obstacles remain to be overcome, the risk-benefit ratio of gene therapy for type 2 diabetes treatments provide better alternative than life long disease management and diet regulation.

\section{Conclusions}

In conclusion, diabetes is a chronic, complex, fast growing disorder worldwide and is potentially preventable. This disorder is serious because of its clinical complications. As evidenced by major clinical trials in the USA and UK, tight control of hyperglycemia, prevents or reduces diabetes-related clinical complications such as retinopathy, neuropathy, nephropathy, skin infections and foot ulcers. Both India and China are racing rapidly towards claiming the title, "Diabetes Capital of the World". Diabetes health care burden will be serious in developing countries as well as in resource poor countries of the world. Development of affordable multi-functional diagnostic platforms, will facilitate the detection of various risk factors at the earliest stages of this disease, as well as help us follow the progression and regression of the disease. Effective, integrated management of the known risks will slow/reduce or prevent diabetes related clinical complications. Both India and China have well-established Traditional Medical Systems, and therefore with the holistic approach, it is possible to develop new and novel approaches to the management of this complex metabolic disorder. A better understanding of the underlying causes that promote various clinical complications of diabetes and developing novel ways to manage the postprandial glucose peaks will reduce the health care cost considerably.

\section{References}

1. Rao GHR, Kakka V (2001) Coronary Artery Disease in South Asians: Epidemiology, Risk Factors, Prevention. Jaypee Medical Publishers, New Delhi, India.

2. Rao GHR, Thankikachalam S (2005) Coronary Artery Disease: Risk Factors Pathophysiology and Prevention. Jaypee Medical Publishers, New Delhi, India

3. Mohan V, Rao GHR (2007) Type 2 Diabetes in South Asians: Epidemiology, Risk Factors and Prevention. Jaypee Medical Publishers, New Delhi, India.

4. Fall CH, Stein CE, Kumaran K, Cox V, Osmond C, et al. (1998) Size at birth, maternal weight, and type 2 diabetes in South India. See comment in PubMed Commons below Diabet Med 15: 220-227.

5. Hill JC, Krishnaveni GV, Annamma I, Leary SD, Fall CH (2005) Glucose tolerance in pregnancy in South India: relationships to neonatal anthropometry See comment in PubMed Commons below Acta Obstet Gynecol Scand 84 159-165.

6. Krishnaveni GV, Hill JC, Veena SR, Leary SD, Saperia J, et al. (2005) Truncal adiposity is present at birth and in early childhood in South Indian children. See comment in PubMed Commons below Indian Pediatr 42: 527-538.

7. Krishnaveni GV, Hill JC, Veena SR, Bhat DS, Wills AK, et al. (2009) Low plasma vitamin B12 in pregnancy is associated with gestational 'diabesity' and later diabetes. See comment in PubMed Commons below Diabetologia 52: 23502358.

8. Krishnaveni GV, Veena SR, Wills AK, Hilla JC, Karat SC, et al. (2010) Adiposity, insulin resistance and cardiovascular risk factors in 9-10 year-old Indian Children: relationships with birth size and postnatal growth. J Develop Origin of health and Disease 1:403-411.

9. Krishnaveni GV, Veena SR, Hill JC, Kehoe S, Karat SC, et al. (2010) Intrauterine exposure to maternal diabetes is associated with higher adiposity and insulin resistance and clustering of cardiovascular risk markers in Indian children. See comment in PubMed Commons below Diabetes Care 33: 402-404.

10. Krishnaveni GV, Veena SR, Karat SC, Yajnik CS, Fall CH. (2014) Association between maternal folate concentrations during pregnancy and insulin resistance in Indian Children. Diabetologia 57:110-112.

11. Veena SR, Krishnaveni GV, Fall CH (2012) Newborn size and body composition as predictors of insulin resistance and diabetes in the parents: Parthenon Birth Cohort Study, Mysore, India. See comment in PubMed Commons below Diabetes Care 35: 1884-1890.

12. Kehoe SH, Krishnaveni GV, Veena SR, Guntupalli AM, Margetts BM, et al (2014) Diet patterns are associated with demographic factors and nutritional status in South Indian children. See comment in PubMed Commons below Matern Child Nutr 10: 145-158.

13. Xiao X, Zhang ZX, Li WH, Feng K, Sun Q, et al. (2010) Low birth weight is associated with components of the metabolic syndrome. See comment in PubMed Commons below Metabolism 59: 1282-1286.

14. Silveira VM, Horta BL (2008) [Birth weight and metabolic syndrome in adults: meta-analysis]. See comment in PubMed Commons below Rev Saude Publica 42: $10-18$.

15. Mi J, Cheng H, Zhao XY, Hou DQ, Chen FF et al. (2008) Developmental origin of metabolic syndrome: interaction of thinness at birth and overweight during adult life in Chinese population. Obes Rev 9: 91-94.

16. Kahn BB, Flier JS (2000) Obesity and insulin resistance. See comment in PubMed Commons below J Clin Invest 106: 473-481.

17. Yusuf S, Hawken S, Ounpuu S, Bautista L, Franzosi MG et al. (2005) Obesity and the risk of myocardial infarction in 27,000 participants: A case-control study. Lancet 366:1640-1649. 
Citation: Rao GHR, Gandhi PG, Sharma V (2014) Clinical Complications of Type-2 Diabetes Mellitus in South Asian and Chinese Populations: An Overview. J Diabetes Metab 5: 420 doi:10.4172/2155-6156.1000420

18. Yajnik CS (2004) Obesity epidemic in India: intrauterine origins? Proc Nutr Soc 63: $387-396$

19. Gray RS, Fabsitz RR, Cowan LD, Lee ET, Welty TK, et al. (2000) Relation of generalized and central obesity to cardiovascular risk factors and prevalent coronary heart disease in a sample of American Indians: the Strong Heart Study. Int J Obes Relat Metab Disord 24: 849-860.

20. Skilton MR, Celermajer DS (2006) Endothelial dysfunction and arterial abnormalities in childhood obesity. Int J Obes (Lond) 30: 1041-1049.

21. Kelly AS, Gonzalez-Campoy JM, Rudser KD, Katz H, Metzig AM, et al. (2012) Carvedilol-lisinopril combination therapy and endothelial function in obese individuals with hypertension. J Clin Hypertens (Greenwich) 14: 85-91

22. Kelly AS, Wetzsteon RJ, Kaiser DR, Steinberger J, Bank AJ, et al. (2004) Inflammation, insulin, and endothelial function in overweight children and adolescents: the role of exercise. J Pediatr 145: 731-736.

23. Watts K, Beye P, Siafarikas A, Davis EA, Jones TW, et al. (2004) Exercise training normalizes vascular dysfunction and improves central adiposity in obese adolescents. J Am Coll Cardiol 43: 1823-1827.

24. Hambrecht R, Wolf A, Gielen S, Linke A, Hofer J, et al. (2000) Effect of exercise on coronary endothelial function in patients with coronary artery disease. $\mathrm{N}$ Engl J Med 342: 454-460.

25. Mather KJ, Steinberg HO, Baron AD (2003) Weight loss and endothelia function in obesity. Diabetes Care 26: 1927-1928.

26. The effect of intensive treatment of diabetes on the development and progression of long-term complications in insulin-dependent diabetes mellitus. The Diabetes Control and Complications Trial Research Group. N Engl J Med 329: 977-986.

27. Nawale RB, Mourya VK, Bhise SB (2006) Non-enzymatic glycation of proteins: a cause for complications in diabetes. Indian J Biochem Biophys 43: 337-344.

28. Méndez JD, Xie J, Aguilar-Hernández M, Méndez-Valenzuela V (2010) Molecular susceptibility to glycation and its implication in diabetes mellitus and related diseases. Mol Cell Biochem 344: 185-193.

29. Akbari CM, Saouaf R, Bamhill DF, Newmann PA, LoGerf FW et al. (2001) Endothelium-dependent vasodilatation is impaired in both micro circulation and microcirculation impaired by acute hyperglycaemia in humans. Circ. 103:16181623

30. Kawahito S, Kitahata H, Oshita S (2009) Problems associated with glucose toxicity: role of hyperglycemia-induced oxidative stress. World J Gastroenterol 15: 4137-4142

31. Du Y, Miller CM, Kern TS (2003) Hyperglycemia increases mitochondria superoxide in retina and retinal cells. Free Radic Biol Med 35: 1491-1499.

32. van Dam PS (2002) Oxidative stress and diabetic neuropathy: pathophysiological mechanisms and treatment perspectives. See comment in PubMed Commons below Diabetes Metab Res Rev 18: 176-184.

33. Ametov AS, Barinov A, Dyck PJ, Hermann R, Kozlova N, et al. (2003) The sensory symptoms of diabetic polyneuropathy are improved with alpha-lipoic acid: the SYDNEY trial. Diabetes Care 26: 770-776.

34. Prabhakar S, Starnes J, Shi S, Lonis B, Tran R (2007) Diabetic nephropathy is associated with oxidative stress and decreased renal nitric oxide production. $J$ Am Soc Nephrol 18: 2945-2952.

35. Kowluru RA, Chan PS (2007) Oxidative stress and diabetic retinopathy. Exp Diabetes Res 2007: 43603

36. Rolo AP, Palmeira CM (2006) Diabetes and mitochondrial function: role of hyperglycemia and oxidative stress. Toxicol Appl Pharmacol 212: 167-178.

37. Lee JY, Lee DC1, Im JA2, Lee JW1 (2014) Mitochondrial DNA copy number in peripheral blood is independently associated with visceral fat accumulation in healthy young adults. Int J Endocrinol 2014: 586017.

38. Berg AH, Scherer PE (2005) Adipose tissue, inflammation, and cardiovascular disease. Circ Res 96: 939-949.

39. Misra A, Misra R (2003) Asian indians and insulin resistance syndrome: global perspective. Metab Syndr Relat Disord 1: 277-283.

40. Misra A, Misra R, Wijesuriya M (2007) The metabolic syndrome. In: Type-2 diabetes in south Asians: Epidemiology, Risk factors and prevention. Mohan $V$ \& Rao GHR (Eds.,), JP Medical Publishers, New Delhi, India.
41. Deepa M, Deepa $R$, Mohan V (2007) Metabolic syndrome in urban south Indians-Assessment by WHO, ATP111 and IDF criteria. In: Type-2 diabetes in south Asians: Epidemiology, risk facts and prevention. Moahn V \& Rao GHR (Eds.,) JP Medical Publishers, New Delhi, India.

42. Gupta R, Deedwania C (2007) The metabolic syndrome and obesity: Management issues. In: Type-2 diabetes in south Asians: Epidemiology, Risk factors and prevention. Mohan V \& Rao GHR (Eds.,), JP Medical Publishers, New Delhi, India.

43. Eckel RH, Grundy SM, Zimmet PZ (2005) The metabolic syndrome. Lancet 365: $1415-1428$

44. Stampler J (2005) Established major coronary risk factor: historical review. In Coronary heart disease epidemiology from aetiology to public health. Marmot M \& Elliot P (Eds.,), (2nd Edn.,), Oxford University Press.

45. Tousoulis D, Kampoli AM, Papageorgiou N, Androulakis E, Antoniades C, et al. (2011) Pathophysiology of atherosclerosis: the role of inflammation. Curr Pharm Des 17: 4089-4110.

46. Koenig W (2001) Inflammation and coronary heart disease: an overview. Cardiol Rev 9: 31-35.

47. Hansson GK (2005) Inflammation, atherosclerosis, and coronary artery disease. N Engl J Med 352: 1685-1695

48. Hansson GK, Robertson AK, Söderberg-Nauclér C (2006) Inflammation and atherosclerosis. Annu Rev Pathol 1: 297-329.

49. Libby P, Ridker PM, Maseri A (2002) Inflammation and atherosclerosis. Circulation 105: 1135-1143.

50. Zebrack JS, Anderson JL (2002) Role of inflammation in cardiovascula disease: how to use C-reactive protein in clinical practice. Prog Cardiovasc Nurs 17: 174-185.

51. Rifai N, Ridker PM (2001) High-sensitivity C-reactive protein: a novel and promising marker of coronary heart disease. Clin Chem 47: 403-411.

52. Duprez DA, Cohn JN (2008) Identifying early cardiovascular disease to targe candidates for treatment. J Clin Hypertens (Greenwich) 10: 226-231.

53. Safar ME, Girerd X, Laurent S (1996) Structural changes of large conduit arteries in hypertension. J Hypertens 14: 545-555.

54. Franklin SS (2005) Arterial stiffness and hypertension: a two-way street? Hypertension 45: 349-351.

55. Davignon J, Ganz P (2004) Atherosclerosis: Evolving vascular biology and clinical implications. Role of endothelial dysfunction in atherosclerosis. Circ. 109: suppl: 111, 27-32

56. Deanfield JE, Halcox JP, Rabelink TJ (2007) Endothelial function and dysfunction: testing and clinical relevance. See comment in PubMed Commons below Circulation 115: 1285-1295.

57. Lerman A, Sandok EK, Hildebrand FL Jr, Burnett JC Jr (1992) Inhibition of endothelium-derived relaxing factor enhances endothelin-mediated vasoconstriction. Circulation 85: 1894-1898.

58. Gomez-Alamillo C, Juncos LA, Cases A, Haas JA, Romero JC (2003) Interaction between vasoconstrictor and vasodilators in regulating hemodynamics of distinct vascular beds. Circ42: 831-836

59. Rao GHR, Gandhi PG (2014) Need for a Non-Invasive Diagnostic Platform for Early Detection and Management of Cardio-Metabolic Disorders. J Clin Prevent Cardiology (In Press).

60. Anne Forgat-Campagna, Venkat Narayan KM (2001) Type-2 diabetes in children Exemplifies the growing problem of chronic diseases. BMJ 322:377-378.

61. Patwaradhan B (2014) Death of Drugs and Rebirth of Health Care: Indian Response to Discovery Impasse. In: Collaborative Innovation in Drug Discovery. R Chaguturu (Ed.,), John Wiley and Sons Inc, USA.

62. Rao GHR, Gandhi PG (2014) Integrative Medicine: Global Perspective. J Homeo and Ayurved Medicine. (In Press).

63. Giugliano D, Ceriello A, Esposito K (2008) Are there specific treatments for the metabolic syndrome? Am J Clin Nutr 87: 8-11.

64. Esposito K, Marfella R, Ciotola M, Di Palo C, Giugliano F, et al. (2004) Effect of a mediterranean-style diet on endothelial dysfunction and markers of vascula inflammation in the metabolic syndrome: a randomized trial. JAMA 292: 14401446. 
Citation: Rao GHR, Gandhi PG, Sharma V (2014) Clinical Complications of Type-2 Diabetes Mellitus in South Asian and Chinese Populations: An Overview. J Diabetes Metab 5: 420 doi:10.4172/2155-6156.1000420

Page 8 of 8

65. Setola E, Monti LD, Galluccio E, Palloshi A, Fragasso G et al. (2004) Insulin resistance and endothelial function are improved after folate and vitamin B12 therapy in patients with metabolic syndrome: relationship between homocysteine levels and hyperinsulinemia. Eur J Endocrinol 151:483-89.

66. Ebrahimi M, Ghayour-Mobarhan M, Rezaiean S, Hoseini M, Parizade SM, et al (2009) Omega-3 fatty acid supplements improve the cardiovascular risk profile of subjects with metabolic syndrome, including markers of inflammation and auto-immunity. Acta Cardiol 64: 321-327.

67. Ruggenenti P, Cattaneo D, Loriga G, Ledda F, Motterlini N, et al. (2009) Ameliorating hypertension and insulin resistance in subjects at increased cardiovascular risk: effects of acetyl-L-carnitine therapy. Hypertension 54: 567 574.

68. Bose M, Lambert JD, Ju J, Reuhl KR, Shapses SA, et al. (2008) The majo green tea polyphenol, (-)-epigallocatechin-3-gallate, inhibits obesity, metabolic syndrome, and fatty liver disease in high-fat-fed mice. J Nutr 138: 1677-1683.

69. Oh S, Lee M, Ko KS, Choi S, Kim SW (2003) GLP-1 gene delivery for the treatment of type 2 diabetes. Mol Ther 7: 478-483.

70. Jean M, Alameh M, Buschmann MD, Merzouki A (2011) Effective and safe gene-based delivery of GLP-1 using chitosan/plasmid-DNA therapeutic nanocomplexes in an animal model of type 2 diabetes. Gene Ther 18: 807-816.

71. Kumar M, Hunag Y, Glinka Y, Prud'homme GJ, Wang Q (2007) Gene therapy of diabetes using a novel GLP-1/lgG1-Fc fusion construct normalizes glucose levels in db/db mice. Gene Ther 14: 162-172.

72. Kay MA, Glorioso JC, Naldini L (2001) Viral vectors for gene therapy: the art of turning infectious agents into vehicles of therapeutics. Nat Med 7: 33-40.

73. Li Z, Düllmann J, Schiedlmeier B, Schmidt M, von Kalle C, et al. (2002) Murine leukemia induced by retroviral gene marking. Science 296: 497 .
74. Sanlioglu AD, Altunbas HA, Balci MK, Griffith TS, Sanlioglu S (2012) Insulin gene therapy from design to beta cell generation. Expert Rev Mol Med 14: e18.

75. Doerschug K, Sanlioglu S, Flaherty DM, Wilson RL, Yarovinsky T, et al. (2002) First-generation adenovirus vectors shorten survival time in a murine model of sepsis. J Immunol 169: 6539-6545.

76. Sanlioglu S, Monick MM, Luleci G, Hunninghake GW, Engelhardt JF (2001) Rate limiting steps of AAV transduction and implications for human gene therapy. Curr Gene Ther 1: 137-147.

77. Sanlioglu S, Duan D, Engelhardt, JF (1999) Two independent molecular pathways for recombinant adeno-associated virus genome conversion occur after UV-C and E4orf6 augmentation of transduction. Human Gene Therapy 10: $591-601$.

78. Wang Z, Ma HI, Li J, Sun L, Zhang J, et al. (2003) Rapid and highly efficient transduction by double-stranded adeno-associated virus vectors in vitro and in vivo. Gene Ther 10: 2105-2111.

79. Riedel MJ, Gaddy DF, Asadi A, Robbins PD, Kieffer TJ (2010) DsAAV8mediated expression of glucagon-like peptide-1 in pancreatic beta-cells ameliorates streptozotocin-induced diabetes. Gene Ther 17: 171-180.

80. Gaddy DF, Riedel MJ, Pejawar-Gaddy S, Kieffer TJ, Robbins PD (2010) In vivo expression of HGF/NK1 and GLP-1 From dsAAV vectors enhances pancreatic B-cell proliferation and improves pathology in the $\mathrm{db} / \mathrm{db}$ mouse model of diabetes. Diabetes 59: 3108-3116.

81. Katano H, Kok MR, Cotrim AP, Yamano S, Schmidt M, et al. (2006) Enhanced transduction of mouse salivary glands with AAV5-based vectors. Gene Ther 13: $594-601$.

82. Di Pasquale G, Dicembrini I, Raimondi L, Pagano C, Egan JM, et al. (2012) Sustained exendin-4 secretion through gene therapy targeting salivary glands in two different rodent models of obesity/type 2 diabetes. PLoS One 7: e40074 